\title{
Retraction Note to: Support vector regression methodology for prediction of input displacement of adaptive compliant robotic gripper
}

\author{
Dalibor Petković $^{1}$ - Shahaboddin Shamshirband ${ }^{2,3}$. Hadi Saboohi ${ }^{4,5}$. \\ Tan Fong Ang $^{3}$ - Nor Badrul Anuar ${ }^{3}$ - Nenad D. Pavlović ${ }^{1}$
}

Published online: 19 November 2018

(C) Springer Science+Business Media, LLC, part of Springer Nature 2018

\section{Retraction Note to: Appl Intell (2014) 41:887-896 \\ http://doi.org/10.1007/s10489-014-0574-5}

The Editor-in-Chief has retracted this article [1] because validity of the content of this article cannot be verified. This article showed evidence of substantial text overlap (most notably with the articles cited $[2,3]$ ) and authorship manipulation. The authors have not responded to correspondence about this retraction.
The online version of the original article can be found at https://oi.org/ 10.1007/s10489-014-0574-5.

Dalibor Petković

dalibortc@gmail.com

Shahaboddin Shamshirband

shahab1396@gmail.com

1 Faculty of Mechanical Engineering, Deparment for Mechatronics and Control, University of Niš, Aleksandra Medvedeva 14, Niš 18000 , Serbia

2 Department of Computer Science, Chalous Branch, Islamic Azad University (IAU), 46615-397, Chalous, Mazandaran, Iran

3 Department of Computer System and Technology, Faculty of Computer Science and Information Technology, University of Malaya, 50603 Kuala Lumpur, Malaysia

4 Department of Information System, Faculty of Computer Science and Information Technology, University of Malaya, 50603 Kuala Lumpur, Malaysia

5 Computer Engineering Department, Islamic Azad University of Karaj, Karaj, Iran

\section{References}

1. Petkovic D, Shamshirband S, Saboohi H et al (2014) Support vector regression methodology for prediction of input displacement of adaptive compliant robotic gripper. Appl Intell 41:887-896. https:// doi.org/10.1007/s10489-014-0574-5

2. Petkovic D, Shamshirband S, Saboohi H et al (2014) RETRACTED: Evaluation of modulation transfer function of optical lens system by support vector regression methodologies - A comparative study. Infrared Phys Technol 65:94-102. https://doi.org/10.1016/j. infrared.2014.04.005

3. Ramedani Z, Omid M, Keyhani A, Shamshirband S, Khoshnevisan B (2014) Potential of radial basis function based support vector regression for global solar radiation prediction. Renew Sust Energ Rev 39:1005-1011. https://doi.org/10.1016/j.rser.2014.07.108 